\title{
Mapping local density of young Eucalyptus plantations by individual tree detection in high spatial resolution satellite images
}

Jia Zhou ${ }^{a, b}$, Christophe Proisy ${ }^{c}$, Xavier Descombes $^{b}$, Guerric le Maire ${ }^{d, e}$, Yann Nouvellon $^{d, f}$, José-Luiz Stape ${ }^{g}$, Gaëlle Viennois ${ }^{h}$, Josiane Zerubia ${ }^{b}$, Pierre Couteron $^{c}$

a. Université de Montpellier 2, UMR AMAP, Boulevard de la Lironde, TA-A51/PS2, Montpellier Cedex 5, F-34398 France

\section{iia.zhou@cirad.fr}

b. Institut National de Recherche en Informatique et Automatique (INRIA), SophiaAntipolis Méditerranée, BP 93, 2004 Route des Lucioles, Sophia-Antipolis Cedex, F-06902 - France

xavier.descombes@inria.fr; josiane.zerubia@inria.fr

c. Institut de Recherche pour le Développement (IRD), UMR AMAP, Boulevard de la Lironde, TA-A51/PS2, Montpellier Cedex 5, F-34398 France christophe.proisy@ird.fr; pierre.couteron@ird.fr

d. CIRAD, UMR Eco\&Sols, 2 Place Viala, Montpellier, F-34060 France guerric.le maire@cirad.fr; yann.nouvellon@cirad.fr

e. CIRAD, UMR TETIS, Maison de la Télédétection, Montpellier Cedex 5, F-34093 France

f. Atmospheric Sciences Department, Universidade de São Paulo, Rua do Matão 1226, 05508-090 São Paulo, Brazil

g. Department of Forestry and Environmental Sciences, North Carolina State University, Raleigh, NC 27695, United States stape@ncsfnc.cfr.ncsu.edu

h. Centre National de la Recherche Scientifique (CNRS), UMR AMAP, TA A51 PS 2, Boulevard de la Lironde, Montpellier Cedex 5, F-34398, France gaelle.viennois@cirad.fr 


\begin{abstract}
Local tree density may vary in young Eucalyptus plantations under the effects of environmental conditions or inadequate management, and these variations need to be mapped over large areas as they have a significant impact on the final biomass harvested. High spatial resolution optical satellite images have the potential to provide crucial information on tree density at an affordable cost for forest management. Here, we test the capacity of this promising technique to map the local density of young and small Eucalyptus trees in a large plantation in Brazil. We use three Worldview panchromatic images acquired at a $50 \mathrm{~cm}$ resolution on different dates corresponding to trees aged 6 , 9 and 13 months and define an overall accuracy index to evaluate the quality of the detection results. The best agreement between the local densities obtained by visual detection and by marked point process modeling was found at 9 months, with only small omission and commission errors and a stable $4 \%$ underestimation of the number of trees across the density gradient. We validated the capability of the MPP approach to detect trees aged 9 months by making a comparison with local densities recorded on 112 plots of $\sim 590 \mathrm{~m}^{2}$ and ranging between 1360 and 1700 trees per hectare. We obtained a good correlation $\left(r^{2}=0.88\right)$ with a root mean square error of 31 trees/ha. We generalized detection by computing a consistent map over the whole plantation. Our results showed that local tree density was not uniformly distributed even in a well-controlled intensivelymanaged Eucalyptus plantation and therefore needed to be monitored and mapped. Use of the marked point process approach is then discussed with respect to stand characteristics (canopy closure), acquisition dates and recommendations for algorithm parameterization.
\end{abstract}

Keywords: crown identification, object detection, stochastic point process, forests, remote sensing, Brazil 


\section{Introduction}

Local density in forest plantations corresponds to a planting density from which local mortality is substrated. It is one of the most important factors controlling the productivity of managed Eucalyptus forests (e.g. Walters, 1980). It directly affects inter-tree competition for light, water and soil nutrients for the whole rotation period (Gonçalves et al., 2004). As young trees are the most sensitive to adverse environmental conditions and inappropriate practices, mortality is likely to occur at early stages. There is thus a silvicultural challenge specifically to locate areas of excessive tree mortality or insufficient growth as soon as possible during the first year in order to decide on replanting accordingly. Areas of strong mortality or poor growth are generally conserved up to the end of the rotation and result in overall lower productivity (Stape et al., 2010). Spatially explicit information about individual Eucalyptus trees may therefore be of great value for pinpointing problems that are often encountered even in intensive plantations due to inadequate management, heterogeneous soil conditions (e.g. Garau et al., 2008), competition with herbaceous vegetation, seed genetic capacity, nutrients supply problems or other local damage (Pallett and Sale, 2004; du Toit et al., 2005). For instance, trees that are rachitic in their early stages are later totally dominated by 'regular' trees, and by the end of the rotation their crown is expected to be under the canopy. Those trees are generally neglected in biomass estimates by companies. Therefore, monitoring the actual number of regular-sized live trees in order to make comparisons with planned density turns out to be of prime importance in the management of extensive forest plantations. However, counting and positioning such young individual trees in the field is generally an unaffordable business when dealing with hundreds of hectares of plantation, as it is frequently observed in Brazil.

The potential of sub-metric spatial resolution remotely sensed data needs to be examined carefully with a view to count young trees at an affordable cost. Published studies have used airborne Light Detection and Ranging (Lidar) and optical satellite instruments. Both types of data can provide fine-scale information on canopy characteristics (e.g. Richardson et al., 2011; Hirschmugl. et al., 2007). The Lidar instruments have a good potential for single tree detection in open canopies (e.g. Tesfamichael et al., 2009; Vauhkonen et al., 2012) or for a forest carbon inventory (e.g. Stephens et al., 2012) due to their ability to measure the vertical structure of forests by 
determining the distance between the sensor and a target within the canopy. However, the cost of airborne Lidar data collection remains high. In Brazil, it ranges from US\$ $15 /$ ha to US $\$ 200 /$ ha depending on the location inside the country, the area covered and the signal density of points (E. Gorgens, pers. comm.). The additional time and cost required for data processing cannot be ignored (Hummel et al., 2011). Consequently, operational use of Lidar remote sensing over extensive Eucalyptus plantations in Brazil is still limited to one-off and well-funded research activities.

On the other hand, space-borne imagery acquired at 0.5 to $1-\mathrm{m}$ resolutions and provided by recent satellites such as Geoeye, Ikonos, Worldview or Quickbird is now increasingly available at reasonable costs ranging from US $\$ 0.10$ for archived images to a maximum of US\$ 0.80/ha in tasking mode (e.g. e-GEOS, 2011). Fast delivery of data, daily revisit and viewing agility are also key characteristics of a forthcoming constellation of small satellites such as Pleiades. In sub-metric optical images, individual tree crowns are visible because of the contrasting sunlit and shadowed parts of the crown itself and also the gaps between neighboring trees. These data can therefore be used to study the canopy aspect of natural tropical forests by conducting a textural analysis and extracting texture indices that correlate with above-ground stand parameters (Couteron et al., 2005; Barbier et al., 2010; Song et al., 2010) and biomass (Proisy et al., 2007). However, canopy texture approaches usually yielded less accurate estimations of stand density than other stand variables such as mean quadratic diameter (e.g. Ploton et al. 2012).

The possibility of automatically detecting individual tree crowns from optical images has been investigated by a variety of techniques, but they all work on pixel intensity to delineate tree crowns from their surrounding environment (Korpela, 2004; Erikson and Olofsson, 2005). A first family of techniques includes local maxima detection (e.g. Pitkänen, 2001; Wulder et al., 2004; Gebreslasie et al., 2011), valley following or region growing (e.g. Gougeon, 1995; Culvenor, 2002), 3D template matching (e.g. Larsen and Rudemo, 1998) or a combination of several of the above (Pouliot and King, 2005). Another family of approaches applies stochastic geometry models to forest scenes. These models can efficiently detect objects by considering both the noise in data and object variability. In remote sensing, marked point process modeling, a subfield of stochastic geometry, would appear to be well suited to the analysis of very high resolution images since it adjusts a random process by considering groups of pixels as parametric, a priori defined objects located in the geographic space (Descombes, 2012). 
The different possibilities opened up by this approach include the counting of items as diverse as brain lesions (Descombes et al., 2004), trees (Perrin et al., 2006) and flamingos (Descamps et al., 2011). Although the review of Larsen et al. (2011) concludes that the above-mentioned individual tree detection techniques show decreasing accuracy with the heterogeneity of forest stands, the marked point process has been found to yield the best results over a forest plantation. The latter study was based on aerial photographs with pixel sizes ranging from 10 to $50 \mathrm{~cm}$. To our knowledge, young stand density has not yet been assessed through individual tree detection from satellite optical imagery.

In this paper, we assess the potential of marked point processes (MPP) to detect individual tree as a contribution to the monitoring of young Eucalyptus plantations from three Worldview images acquired at the ages of 6,9 and 13 months. We first used the results of visual detection by independent assessors to measure the performance of the MPP approach and its sensitivity to parameter values. We then validated the MPP estimations of local tree density using figures from a ground truth dataset of 112 plots. Finally, a local density map was produced across the entire study area i.e. 170 ha. The usefulness and performance of MPP for mapping the early stages of Eucalyptus plantations are finally discussed.

\section{Data}

\subsection{Main characteristics of the Eucalyptus plantation}

This study took place in a plantation managed by the Duratex company. It is located in southeastern Brazil at approximately $22^{\circ} 58^{\prime} \mathrm{S}$ and $48^{\circ} 43.75^{\prime} \mathrm{W}$ (Fig. 1). The area is currently the subject of several research investigations aimed at monitoring and improving the growth of Eucalyptus trees (e.g. Laclau et al., 2010; le Maire et al., 2011a). Mean annual rainfall in the area is around $1300 \mathrm{~mm}$, occurring mainly between October and March. Annual temperatures range from $13.3^{\circ} \mathrm{C}$ in the coldest months (June to August) to $27.2^{\circ} \mathrm{C}$ in the warmest season (December to February), with $19^{\circ} \mathrm{C}$ being the average. In addition, temperatures in the cold season rarely drop below $5^{\circ} \mathrm{C}$. The study area is almost entirely flat except in the western and northwestern part of the stand where the land slopes gently down to a stream. This part of the stand has also a higher 
percentage of clay content and is more prone to encroachment by herbaceous vegetation (Campoe et al., 2012).

The study concerned a surface area of about 170 hectares, as shown in Figure 1. This stand is planted with a company-improved, highly productive clone of Eucalyptus grandis (W. Hill ex Maiden). Clone cuttings have been planted in rows approximately 3 meters apart, and the trees in the rows are about $2 \mathrm{~m}$ apart. This gives a target density of 1666 trees per hectare. Planting operations took place over a period of 3 to 4 weeks from the end of November 2009. The soil was fertilized and chemical weeding was carried out to remove competitors (Garau et al., 2008).

Unloading tracks clearly divide the area into 4 zones labeled $A$ to $D$ (Fig. 1). The four zones have specific plantation row azimuths (Fig. 2) of about $159^{\circ}, 72^{\circ}, 7^{\circ}$ and $8^{\circ}$ from the East. Despite uniform plant material, soil preparation and fertilization (le Maire et al., 2011b; Campoe et al., 2012), each zone shows local productivity gradients related to local differences in topography, soil water, nutrient availability or insufficient weed control. This alters final planting performance by reducing growth or increasing mortality during juvenile stages in the least favorable contexts.

The growth of these trees averages $20-25 \mathrm{Mg}$ of dry matter ha- ${ }^{-1}$ year $^{-1}$, i.e. one of the highest forest productivities in the world (Marsden et al., 2010; le Maire et al., 2011a). Tree crown extension was recorded in four inventory plots of 84 trees each (Fig. 1) in from May to October 2010 by measuring ground projections of both row and inter-row tree crown axes (diameters). Our measurements in May, August and October showed that crown radii were $0.80 \mathrm{~m} \pm 0.22 \mathrm{~m}, 0.99 \mathrm{~m} \pm 0.21 \mathrm{~m}$ and $1.1 \mathrm{~m} \pm 0.16 \mathrm{~m}$ in the plantation row direction and $0.82 \mathrm{~m} \pm 0.24 \mathrm{~m}, 1.06 \mathrm{~m} \pm 0.22 \mathrm{~m}$ and $1.15 \mathrm{~m} \pm 0.16 \mathrm{~m}$ in the orthogonal direction. Interestingly, the dissimilarity between the two directions proved weak over the growing sequence (less than 6\%) and crown projection to ground was therefore approximated as circular discs. After October, no measurements were available but we assumed relative stable crown projections to ground due to the canopy closeness.

\subsection{Validation data}

The validation data included local tree densities collected in May 2010 on 112 plots located at the periphery of the plantation zones (Fig. 1). These plots corresponded to seven replications of clone trials involving sixteen different clones commonly used in commercial Eucalyptus plantations. The 16 clones were very different in terms of leaf 
properties (reflectance, transmittance) and canopy structural characteristics (leaf angles, leaf area index, crown diameters, height, etc.). On each of these 112 plots, 12 rows with 16 trees per row were planted on an approximately $3^{\star} 2 \mathrm{~m}$ regular grid at the same time as the rest of the plantation. Within the central area of each plot, we measured the crown diameters of a total of 96 trees (12 trees per row). The area over which density was actually assessed in each plot was thus around $590 \mathrm{~m}^{2}$. In some plots, mortality occurred between the planting date and the inventory date, and some trees though surviving, had almost no growth. For the study, we considered as 'regular' only the trees that had a crown diameter above $20 \mathrm{~cm}$ in May 2010. The local density on the 112 plots of these regular trees ranged between 1360 and 1700 trees per hectare.

\subsection{Remote sensing images and preprocessing}

The study involved three high spatial resolution Worldview images acquired from May 2010 to January 2011 (Table 1). Only panchromatic data were used. The images were acquired at different viewing angles (Table 1) and were provided in a GeoTiff format at a spatial resolution of 50 centimeters. Sun elevation in the January image was $25^{\circ}$ higher than for May and August. Sun-viewing angle values indicated an almost rear illumination (sun behind) of $20^{\circ}$ for the May acquisition whereas illumination in August and January was from the side, with angles of about 95 and $105^{\circ}$ (Table 1). A preliminary visual examination of the images (Fig. 2) showed how the January image contrasted sharply with the two previously acquired images as being slightly blurred in appearance with plantation rows no longer visible, especially in zones $\mathrm{A}$ and $\mathrm{C}$. We interpreted this as a consequence of high sun elevation combined with the relative azimuth angle of the sensor while the distance between the crowns of Eucalypt trees in adjacent rows had narrowed since August (and crowns adjoined along a row). Indeed, rows in the zone B image were still clearly visible in the January image because the sunlight was coming from a near orthogonal direction of $80^{\circ}$.

The registration of the Worldview-2 images needed to be corrected in order to reach the pixel size precision required to superimpose the three images of the same area. To do this, we took the May image as the reference image for superimposition and located about 100 image-to-image landmarks spread over the stand and the neighboring region in both the August and January images. We then used a third order polynomial to reach a spatial superimposition error of less than $50 \mathrm{~cm}$. 
Lastly, we re-sampled the three superimposed images into $10 \mathrm{~cm}$ pixel images by applying a cubic convolution fit to keep the rectification smooth. This oversampling, as routinely accomplishable by all image processing software, was required to improve the flexibility of disc radius parameter adjustments to the crown in the MPP analysis.

\section{Methods}

The study comprised several operations (Fig. 3) applied to the preprocessed images that could be grouped into five main steps: tree positioning by visual analysis (3.1); automatic detection of trees by MPP (3.2); identification of the best sets of parameters by an analysis of detection quality (3.3); validation from ground-assessed densities before generalization to the whole plantation (3.4). These operations were implemented in Matlab® language.

\subsection{Visual tree positioning}

In our study we assumed that a careful visual analysis of the Worldview images would provide an adequate reference dataset of tree positions for comparison with MPP results (Fig.3; step 2). This is reasonable provided that tree crowns are neither too small (compared to pixel size) nor sufficiently large to fill the inter-crown gaps along the rows. We therefore visually analyzed the August image (9-month-old trees), which was immune to both difficulties and used the May image (6-month-old trees) only for additional comparisons. In addition, we restricted the tedious work of visual interpretation to a sample of training/validation zones given that not only the affordability but also the quality and objectivity of the interpretation process were likely to decrease with the interpreted area. We thus arbitrarily located and delineated a total of 18 square $50 \times 50 \mathrm{~m}$ plots in zones A, B, C and D (Fig. 1) with the aim of interpreting a sample that featured all the different plantation row angles.

Visual detection was carried out by two experts working independently on GIS-based data and consisted in determining latitude and longitude projections of apparent crown centers for all identifiable trees located in each of the 18 plots. About 7,000 trees were located by each of the two experts with close agreement between the two for the number of trees in the plots (correlation coefficient 0.95 ). On the other hand, tree density across the 18 plots varied substantially, but independently of the zones as the number of 
visually detected trees ranged from 358 to 417 , i.e. the maximum number of trees imposed by the plantation scheme for $2500 \mathrm{~m}^{2}$.

\subsection{Tree detection by the marked point process}

The point process theory can be used to build random spatial patterns of points and is part of stochastic geometry. As the reader can find abundant literature on the subject from the mathematical point of view (e.g. Stoyan et al., 1995; van Lieshout, 2000; Jacobsen, 2006), or from an image processing point of view (Descombes, 2012), we present here only the basics of marked point process modeling along with specificities for application to high spatial resolution images of Eucalyptus plantations (Fig. 3; step 2).

\subsubsection{Marked point process modeling from zenithal images of forests}

A high-resolution image of a forest canopy is a two dimensional lattice of spectral reflectance where tree crowns are distinguishable from their surrounding environment by intensity contrasts between sunlit and shadowed canopy portions or soil portions (Proisy et al., 2007). As visual analysis naturally tends to individualize tree crowns, it is sensible and logical to model the image scene as a particular production of a point process having as marks discs that approximate the crown shapes (Fig. 4; left). Each MPP corresponds to a random configuration of discs belonging to the configuration space $X=P \times M$, where $P$ is the space containing the geographic positions of the crown centers, and $M$ is the space containing the marks. In our study, the mark was regarded as the ground-projected crown half-diameter (or radius). Space $X$ was thus defined as:

$$
X=P \times M=\left[0 ; X_{M}\right] \times\left[0 ; Y_{M}\right] \times\left[r_{\min } r_{\max }\right]
$$

where $X_{M}$ is the width and $Y_{M}$ the length of the image scene, and $r_{\min }$ is the minimum value and $r_{\max }$ the maximum value considered for the radius of the discs. The PPM model was defined through a probability density with respect to the Poisson measure (van Lieshout, 2000) and an energy function was stated using a Gibbs formulation (Descombes et al., 2009; Descombes, 2012). Finding the best configuration for the model then became an energy minimization exercise through the space of all possible random configurations featuring a finite number of disc-objects. The total energy $U(x)$ of a given configuration was defined as the sum of two terms, namely:

$U(x)=U_{p}(x)+U_{d}(x)$ 
where $U_{p}(x)$ is a term introducing constraints between two adjacent objects (prior energy) and $U_{d}(x)$ is a term that expressed how well the system made by the objects and their neighborhood fitted image reflectance (data energy). The first term $U_{p}(x)$ cumulates the elementary energy computed for each adjacent pair of objects while the second $U_{d}(x)$ cumulates the local energy and includes variations in pixel values within and around each object in the configuration.

This local data energy $U_{d}(x)$ was computed through a function of the radiometric contrast between the pixels inside a given disc-object and the pixels composing its surrounding annulus. The higher this contrast, the more likely was the existence of a sunlit crown over a shadowed background. Let us note as $\mu_{i}, \sigma_{i}, n_{i}$ and $\mu_{0}, \sigma_{0}, n_{0}$ the mean intensity, standard deviation and number of pixels inside a given disc-object and inside its surrounding ring, respectively. For every disc brighter than its corona i.e. $\mu_{o}<\mu_{i}$, a contrast function derived from a Student's mean-comparison test is computed as follows:

$$
S(x)=\frac{\mu_{1}-\mu_{0}}{\sqrt{\frac{n_{i} \sigma_{i}^{2}+n_{0} \sigma_{0}^{2}}{n_{i}+n_{0}-2}} \sqrt{\frac{1}{n_{i}}+\frac{1}{n_{0}}}}
$$

Then, data energy is derived from the comparison of $S(x)$ with a contrast threshold $T$ ( $T>0$ and $T \leq 1$ ) defined and used as part of model parameterization:

$$
U_{d}(x)=\left\{\begin{array}{c}
\frac{T-S(x)}{T}, \text { if } S(x)>1-T \\
S(x)-1, \text { otherwise }
\end{array}\right.
$$

when $S(x)<1-T, U_{d}(x)<0$, the disc fits the data. Setting the contrast threshold to a low value tends to increase the number of discs accepted around the same location, while high values of $T$ may increase omissions in the event of low contrasts.

The prior energy term $U_{p}(x)$ is defined here to penalize any overlap between two objects and is a function of the normalized extent of the discs' intersection (Fig. 4; left). This function is parameterized using an overlapping threshold value, noted $\theta$, that must be adjusted in relation to both image characteristics and forest type. Finally, overall prior energy is described as $U_{p}(x)=\gamma \eta(x)$, where $\eta(x)$ is the number of disc pairs with nonnull intersection in the current configuration and $\gamma$ is a parameter that weights prior energy comparatively to data energy $U_{d}(x)$.

\subsubsection{Multiple Births and Deaths optimization algorithm}


In order to find the $\boldsymbol{x}$ configuration that minimized total energy $U(x)$, we used a 'multiple births and deaths' process. The algorithm, embedding an annealing technique, was first proposed in Descombes et al. (2009) and consists of the following steps:

1) Initialize both a temperature $\beta$ to 1 and a birth rate $\delta=\frac{X_{M} \times Y_{M}}{r_{\max }}$

2) Select image pixels randomly from those not yet associated with a disc. Then, select discs with radius between $r_{\min }$ and $r_{\max }$ randomly from the newly born disc radius. a uniform distribution.

3) Sort the discs of the current configuration with respect to their data energy in decreasing order (i.e. from the worst to the best cases).

4) Remove each disc with a probability depending on both the temperature parameter and the total energy difference between the configurations with and without this object.

5) If the process has not converged (i.e. if total energy changes significantly during the last iteration), both temperature and birth rate are decreased.

\subsection{Identifying the best sets of parameters}

MPP modeling was applied to the 18 image extracts (each of $50 \times 50 \mathrm{~m}$ ). The range of disc radius variations was adjusted based on field measurements of the radii of a sample of crowns at the three plantation ages considered (see 2.1). The $\left[r_{\min }, r_{\max }\right]$ pairs values used to analyze the January image were taken according to the October measurements, assuming minor changes in canopy dimensions afterwards due to canopy closure. The largest interval range for $\left[r_{\min }, r_{\max }\right]$ pairs was thus set to $[5,10],[7,12]$ and $[9,15]$ pixels in the analysis of the May, August and January $10 \mathrm{~cm}$ oversampled images, respectively. Various values for $\gamma, T$ and $\theta$ were also used (see 4.1). For each parameters combination, all detected disc-objects (center coordinates plus radius) were drawn and overlaid on the analogue patterns provided by the visual interpretation of each expert (Fig. 3; step 3). A search was conducted for all detected discs located within a capture distance of less than the maximum radius of the tree crown expected at a given observation date. Capture distance was taken from field measurements to be the average tree crown half diameter at the considered age plus one standard deviation of the related crown radius distribution.

When only one disc was captured in the neighborhood of a known tree, the detection was considered as validated (situation 1). Detection process limitations generated three 
other possible situations: no discs captured (situation 2), multiple captures (situation 3), and false detection i.e. no reference position could be associated with a given detected disc (situation 4). We therefore defined four variables for characterizing the quality of detection for any given set of parameters. Situation 1 (one tree, one disc) was described through the number of validated discs (noted $n b v$ ). Situation 2 informs on omission error as quantified by the number of omitted discs ( $n b o$ ) whereas situations 3 and 4 contribute to the commission error through the number of multiple detections $(n b m)$ and the number of false detections ( $n b f)$. The number of trees visually detected was noted $n b r$. Associated rates were then computed from ratios of $n b v, n b o, n b l$ or $n b v$ on $n b r$.

Finally, and as done in several other studies (e.g. Pitkänen, 2001; Pouliot et al., 2005) we used an overall accuracy index, noted $A l$, to measure the performance of any given set of parameters:

$$
A l(\%)=\frac{n b v}{n b v+n b o+n b m+n b f} \times 100
$$

This index corrects the validated rate by taking account both of omission and commission errors. It should be noted that computation of this overall index was strictly dependent upon the availability of reference data for tree locations.

\subsection{Local density validation and large-scale mapping}

We validated the potential of the MPP to detect young Eucalyptus trees by comparing local density values estimated by MPP with fully independent data coming from the 112 field plots measuring $\sim 590 \mathrm{~m}^{2}$ as previously presented. Only the best set of parameters that minimized unavoidable omission and commission errors was used (Fig. 3; step 4).

Our last aim was to compute a MPP-derived local density map for the entire plantation area from the number of MPP-detected discs (Fig. 3; step 5). In order to cover the whole Eucalyptus plantation imaged by Worldview, the local density index had to be computed over approximately 800 image windows (each of $50 \times 50 \mathrm{~m}$ ), i.e. about 170 hectares of plantation. We also indicated an error index for MPP-detection by averaging the number of omitted, redundant and false discs, noted nboe, nbme and nbfe, respectively.

For information, it takes around 20 minutes to process a $50 \times 50 \mathrm{~m}$ image (500x500 pixels) extracted using a Matlab ${ }^{\circledR}$ routine on a $3.5 \mathrm{GHz} 64$ bit PC running with a conventional RAM configuration of a few gigabytes. Processing time increases with the specified range of radii. 


\section{Results}

The quality of MPP detections was analyzed in two steps. The first aimed to identify both the parameters $(\gamma, T, \theta)$ and observation dates that maximized the overall accuracy index. It was carried out using broad ranges of crown radius values. The second step evaluated how the range of crown values, i.e. $\left[r_{\min }, r_{\max }\right]$ pairs affected the final results.

\subsection{Selecting tree detection parameters}

\subsubsection{MPP parameters}

The May, August and January images were analyzed using various pairs of minimum and maximum radius values, i.e. [5, 8], [8, 10] and [10, 12] pixels, respectively. Detection scores were systematically computed in reference to the two visual expert appraisals. For the sake of conciseness, only a subset of the results and figures obtained is presented in this paper.

Detection scores varied only by a few percentage points when data energy threshold value $T$ was varied from 0.05 to 0.8 (not shown). This parameter was therefore set to 0.1 in subsequent analyses, without any great loss of generality. The effect of the $\gamma$ parameter that weights prior energy relative to data energy was also tested by considering values ranging from 0.5 to 6 . For each value of $\gamma$, we simultaneously examined the effect of the overlapping threshold by taking $0 \leq \theta \leq 0.5$. The results obtained for all observation dates and all $\theta$ values showed that setting $\gamma$ below 1 generated far too many multiple detections while $\gamma$ values above 1 reduced multiple detections to less than $15 \%$ for the May image and to around $10 \%$ for both the August and January images (result not shown). Also, overall detection quality was stable for all values of $\gamma \geq 1$. Thus, for the remainder of the study, $\gamma$ was set to 2 .

Variations in detection scores were analyzed by considering a range of overlapping threshold $\theta$ values from 0 (no overlap) to very high values of up to 0.5 for May and August (50\% overlapping) and 0.7 for January. We observed that the overall accuracy index for the May image (Fig 5; top) was relatively stable at about $60 \%$, with $\theta$ less than 0.2. Beyond this value, the overall accuracy index rapidly deteriorated due to a simultaneous decrease in validated detections and an increase in multiple detections. 


\subsubsection{Image acquisition date}

As shown in figure 5, the accuracy index Al for MPP-based detections was clearly higher when using the August image than when using the May and January images, with mean values of $82 \%, 51 \%$ and $30 \%$, respectively.

Considering the May acquisition, index values were about $70 \%$ as long as the overlapping threshold $\theta$ remained below 0.2 , but then fell to $40 \%$ (Fig 5; top). The rate of missed detections exceeded $15 \%$ while that of validated detections (single detections) was less than $60 \%$. Conversely, the August image clearly provided good overall scores exceeding $80 \%$ when using $0.05 \leq \theta \leq 0.3$ (Fig 5; middle). Very poor detection quality was obtained from the January image, with the overall accuracy index peaking at no more than $35 \%$ for $\theta=0.4$ (Fig 5; bottom). Canopy closure along plantation rows due to crown enlargement (Fig. 2) is a likely explanation for this poor performance of the MPP analysis at this plantation age.

However, it should be noted that false detections (disc-objects that cannot be associated with a visually detected tree) were zero for all tested parameters and all observation dates, indicating that the marked point process had been appropriately parameterized.

\subsubsection{Range of disc radii using the August image}

Here we focused on analyzing the August image. The main parameters were set to the previously established values of $\gamma, T$ and $\theta$ in order to determine how the choice of minimal/maximal radius values impacted omission and commission errors and overall detection quality (Table 2 ) for the four zones with different plantation row orientations (Fig. 6).

Since no significant difference was found between the tree density values provided by the two independent visual expert appraisals (see 3.1), densities were considered as a sound basis to compute overall detection scores. Interestingly, the validated detections rate exceeded $82 \%$ for all four zones, showing that row orientation had little or no impact on this result. However, the overall accuracy index indicated that median density values were about $15 \%$ lower in $A$ and $B$ than those observed for zones $C$ and $D$. Rates of no detection and multiple detection ranged from 5 to $8 \%$ in zones $A$ and $B$ while in zones $C$ and $D$ these values did not exceed $3 \%$.

A detailed analysis using various $\left[r_{\min }, r_{\max }\right]$ pairs (Table 2) indicated that the MPP analysis performed least well taking values in the upper part of the realistic tree crown radius interval, i.e. with $r_{\min } \geq 10$ pixels $(1 \mathrm{~m})$, whereas using $\left[r_{\min }, r_{\max }\right]$ pairs close to the 
lower boundary i.e. $[7,11],[8,11]$ or $[9,11]$ boosted both the overall index and the validated rate to values above $90 \%$ by minimizing omission and commissions errors to a few percent. The potential of the MPP analysis is illustrated in Figure 7 which shows examples of the detection results obtained with $\left[r_{\min }, r_{\max }\right]=[9,11]$.

Additionally, a comparison of visually- vs. MPP-detected trees pointed to MPP detection providing a $4 \%$ underestimation, but despite this difference the two assessments appeared to be linearly correlated throughout the range of Eucalyptus tree densities. This indicates that the discrepancy between the visual- and MPP-based density estimates is not density-dependent when considering Worldview images acquired for 9month old Eucalyptus plantations.

\subsection{Validation of MPP-derived local density}

We computed the local density on the 112 validation plots using the best parameter combinations i.e. $T=0.1, \gamma=2$ and $\theta=0.1$ and using one of the best radius ranges, i.e. [7, 11] pixels. The comparison of the MPP-derived and ground truth collected local density values correlated well $\left(r^{2}=0.88\right)$ with a root mean square error of 31 trees/ha (Fig. 8). The slope coefficient of the regression between both datasets did not significantly depart from 1 with a $95 \%$ confidence interval. There was no mean to quantify omissions or commission errors, since ground truth plots did not feature $\mathrm{XY}$ locations of trees. However, this result validated the ability of MPP detection to assess tree density using the parameter values previously identified by visual detection. It also confirmed the robustness of MPP density estimates across gradients of tree densities, tree structural characteristics and row orientations.

\subsection{Large-scale mapping of local density}

Lastly, we generated a local tree density map for the entire plantation ( $~ 800$ image windows of $50 \times 50 \mathrm{~m}$ ) using one of the best radius ranges, i.e. [8, 11] pixels. This parameterization yielded a number of trees ranging from 333 to 420 trees to compare with the 415 theoretically planted trees for a $50 \times 50 \mathrm{~m}$ planted area. The associated values for nboe, nbme, nbfe corresponded to 17,14 and 0 trees, respectively. The resulting map showed local density variations ranging from 316 trees mainly in the 
northwestern part (zone A) to maximum density values in zone D (Fig. 9). Local density across the plantation was clearly not uniformly distributed.

\section{Discussion}

\subsection{Potentialities and further improvements of MPP analysis}

High spatial resolution satellite images can supply useful quantitative information for forest management as they can be used to analyze the forest scene on an individual tree scale. For instance, pixelwise classification algorithms based on optical image radiometry are generally ill-suited to detect young individual trees and measure their characteristics. The problem of tree crown delineation in fine spatial resolution images calls for methods that combine both an analysis of radiometric contrast and a priori knowledge of tree size and physiognomy. In response to this, and once it had been verified that tree crowns can be represented by circular discs, the marked point process modeling of forest image properties has an undeniable potential for monitoring Eucalyptus forest plantations. One particular advantage of using this MPP method is its ability to integrate a priori and ideally field-derived data on forest characteristics when setting the ranges of parameter values that determine point process configurations. Values for disc radii must match realistic ranges of tree crown half-diameters on the observation date in order to avoid false detections and improve MPP performance. Data on tree crown overlapping area are crucial for MPP analysis and can be deduced from ground-truth references in one or more plots. Yet, very little crown overlap is observed in this kind of even-aged Eucalyptus plantation, and, over time, overlap is of very limited importance. The overlap parameter, $\theta$, is therefore more intended to express possible crown deformation that may occur from tree-tree interactions along the plantation rows. Crown modeling via circles cannot account for such deformation plasticity, but allowances made for some overlapping provide the necessary plasticity. However, in our study, field data showed that little crown deformation occurred, and interpretation of the optimal overlap values is probably related to sun and/or sensor position distorting apparent tree position or crown shape.

Some difficulties may arise when transforming radiometric variations expressed as square pixels into disc-objects of adequate size. Here, we found in our preliminary tests that simply oversampling the original image up to $10 \mathrm{~cm}$ pixels greatly improved 
detection as the marked point process functions better when disc-objects are described by tens of pixels rather than a few pixels. More accurate disc positioning through to a finer evaluation of the radiometric distance between a crown and its periphery may improve data energy minimization. This of course relies on choosing an appropriate value for threshold parameter $T$. In our case of Eucalyptus crown detection in Worldview panchromatic images and for the $10 \mathrm{~cm}$ resolution used, a sensitivity analysis led us to the conclusion that substantial variations in $T$ do not significantly affect detection. Dealing with other images such as infrared channels or Lidar-derived canopy-height models would require additional sensitivity testing. Additionally, computation of the radiometric distances needed to evaluate the data energy term may be improved, especially if spatial resolution and pixel numbers are high.

\subsection{Prospects and limitations}

Although the set of parameters used to implement the method is theoretically large, we have shown here that, for a specific class of application (i.e., a certain type of tree stand and a given type of image), most parameters have a limited effect on the result and can be safely assigned to predetermined values. In our study of a Eucalyptus plantation, we noted that we could take $T=0.1$ and $\gamma=2$ as the energy threshold and weighting of data energy, respectively. We also propose that the overlapping parameter may be taken in further studies as $0.1 \leq \theta \leq 0.2$ in the absence of more specific information. The only remaining parameters concern the range of disc radii, which has been shown to have a substantial effect on the results, but which can easily be adapted to each specific case by field measurements of crown radii.

This work highlights that the number of trees and possibly tree locations can be mapped from metric spaceborne images during early growth stages before tree crowns join. Considering Eucalyptus plantations, mapping can be used to illustrate that planting success is heterogeneous in space and pinpoint where the problem of tree mortality or insufficient growth is the most acute. The potential for stand density mapping from individual tree detection must now be tested in diverse types of even-aged, open-canopy stands. For instance, the monitoring of ecosystems marked by frequent primary successions, such as Amazonian mangroves, could benefit from the mapping of natural colonization over extensive mud banks by fast-spreading species such as Avicennia germinans (Proisy et al., 2009). The method could also be used to detect emergent tree 
crowns sparsely distributed over a number of hectares of closed canopy forest, and this could be tested by setting the overlapping threshold and disc radii at values distinct from those observed for canopy trees. However, as suggested by the analysis of the January image, corresponding to trees aged 13 months, tree canopy closeness makes detection impossible with the available native image resolution. In comparison, Vauhkonen et al. (2011) concluded that airborne scanning laser data allowed tree detection during the whole rotation time in $4 \times 3 \mathrm{~m}$ Eucalyptus plantations. Moreover, when considering natural tropical terra firme forests, tree crown size cannot be restricted to a given interval of a few decimeters. In addition, tree crowns often overlap or closely adjust one to another, resulting in non-circular shapes. Hence, any attempt to determine the number of trees per hectare (except emergent/dominant trees) by MPP analysis on images with a spatial resolution of $50 \mathrm{~cm}$ to $1 \mathrm{~m}$ will probably fail in natural forests. A texture analysis providing information on modal crown size on a forest hectare scale (Couteron et al., 2005; Proisy et al., 2007) may be the best way to extract information from images of closed canopies at these resolutions.

\subsection{Prospects for improving the management of Eucalyptus plantations}

Large-scale automatic mapping of local tree density within commercial eucalypt plantations is possible by MPP-based single tree detection. Generated maps contribute to our overall knowledge of plantations, and could influence decision-making by locating site-specific silvicultural failures that reduce productivity. An early detection of high mortality areas could lead to modifications in current fertilization and weeding practices to adapt them more to local low stand density (precision forestry). Local densities are a good indicator of the potential volume at harvest, particularly when combined with information about average individual tree volume obtained from adequate field measurements. The advantage of using imagery compared to forest inventories is that individual-scale and thus local information can be obtained over large areas. A lower than expected tree density can inform the manager of possible problems occurring in that area, and this can either be dealt with directly or at the next rotation. Since the best detection results are obtained when trees are aged 6 to 9 months, this is too late to replace missing trees, but the manager may decide to replant the local area entirely if economically profitable, or change the clone, treatments or other operations at the next rotation. The price of high spatial resolution satellite images will very likely decrease in 
the future while availability will increase. Moreover, the application of such MPP-based analyses at each successive rotation may provide a basis for building temporal archives of plantation performance that may be useful for adjusting stocking densities and management practices. Finally, the potential of the MPP approach will probably increase with its application to fin-scale Lidar-derived canopy heights models that already proved usefulness for monitoring Eucalyptus plantations (e.g. Packalén et al., 2011).

\subsection{Concluding remarks}

A better understanding of how the most influential MPP parameters need to be set for different forest types, tree ages, crown forms and sun and viewing conditions may be obtained by simulating reflectance images using 3D stand mockups and a radiative transfer model, like for instance the DART model (Gastellu-Etchegorry, 2008). Here, as explained by Barbier et al. (2012), realistic canopy images can be simulated by applying the DART model to 3D forest mockups consisting of "lollipop" trees (ellipsoids on a stick) built from field inventories and allometric relationships. This is a very convenient method for developing and testing the robustness of remote sensing methods dedicated to the application of high spatial resolution imagery to forests.

Simulating images of Eucalyptus plantations may help to both adjust the set of MPP parameters for each age (and related levels of total height and crown development) and determine optimal acquisition parameters in terms of sun and viewing angles (le Maire et al., 2012b). This approach may pave the way to providing key attributes for forest management, such as trees location maps, an abacus of crown diameter growth during early stages, and areas of poor growth or high mortality. Information such as this is crucial when investigating the effect of planting density on yield (Vanclay, 1994) or when simulating competition for light (Binkley et al., 2010; le Maire et al., 2012a; Binkley et al., 2012) and when using a simple representation of tree crowns with geometrical volumes, such as ellipsoids or cones (Medlyn, 2004).

\section{Acknowledgements}

This work was supported by the ORFEO program, a Centre National d'Etudes Spatiales (CNES) Accompaniment Program for the use of PLEIADES images. We especially wish to thank Claire Tinel for her help in image sorting and are grateful to the Eucflux project 
(http://www.ipef.br/eucflux/) for providing inventories of the Eucalyptus plantation plots. We thank Peter Biggins for the revision of the English.

\section{References}

Barbier, N., Couteron, P., Proisy, C., Malhi, Y., \& Gastellu-Etchegorry, J.-P., 2010. The variation of apparent crown size and canopy heterogeneity across lowland Amazonian forests. Global Ecology and Biogeography, 19, 72-84.

Barbier, N., Couteron, P., Gastelly-Etchegorry, J.-P., Proisy, C., 2012. Linking canopy images to forest structural parameters: potential of a modeling framework. Annals of Forest Science 69, 305-311.

Binkley, D., Stape, J.L., Bauerle, W.L., Ryan, M.G., 2010. Explaining growth of individual trees: Light interception and efficiency of light use by Eucalyptus at four sites in Brazil. Forest Ecology and Management 259, 1704-1713.

Binkley, D., Campoe, O.C., Gspaltl, M., Forrester, D.I., 2012. Light absorption and use efficiency in forests: Why patterns differ for trees and stands. Forest Ecology and Management. doi:10.1016/j.foreco.2011.11.002

Campoe, O.C., Stape, J.L., Laclau, J.-P., Marsden, C., Nouvellon, Y., 2012. Stand-level patterns of carbon fluxes and partitioning in a Eucalyptus grandis plantation across a gradient of productivity, in São Paulo State, Brazil. Tree Physiology. doi:10.1093/treephys/tps038

Couteron, P., Pélissier, R., Nicolini, E., Paget, D., 2005. Predicting tropical forest stand structure parameters from Fourier transform of very high-resolution remotely sensed canopy figures. Journal of Applied Ecology 42, 1121-1128.

Culvenor, D.S., 2002. TIDA: an algorithm for the delineation of tree crowns in high spatial resolution remotely sensed imagery. Computers \& Geosciences 28, 33-44.

Descamps, S., Béchet, A., Descombes, X., Arnaud, A., Zerubia, J., 2011. An automatic counter for aerial images of aggregations of large birds. Bird Study 58, 302-330.

Descombes, X., Kruggel, F., Wollny, G., Gertz, H.J., 2004. An object-based approach for detecting small brain lesions: application to Virchow-Robin spaces IEEE Transactions on Medical Imaging 23, 246-255.

Descombes, X., Minlos, R., Zhizhina, E., 2009. Object Extraction Using a Stochastic Birth-and-Death Dynamics in Continuum. Journal of Mathematical Imaging and Vision 33, 347-359. 
Descombes, X. (Ed.), 2012. Stochastic Geometry for Image Analysis. ISTE \& John Wiley \& Sons.

du Toit, B., Dovey, S.B., 2005. Effect of site management on leaf area, early biomass development, and stand growth efficiency of a Eucalyptus grandis plantation in South Africa. Canadian Journal of Forest Research 35, 891-900.

eGeos, 2011. Price List. http://www.eurimage.com/products/prices_terms.html

Erikson, M., Olofsson, K., 2005. Comparison of three individual tree crown detection methods. Machine Vision and Applications 16, 258-265.

Garau, A.M., Lemcoff, J.H., Ghersa, C.M., Beadle, C.L., 2008. Water stress tolerance in Eucalyptus globulus Labill. subsp. maidenii (F. Muell.) saplings induced by water restrictions imposed by weeds. Forest Ecology and Management 255, 2811-2819.

Gastellu-Etchegorry, J.P., 2008. 3D modeling of satellite spectral images, radiation budget and energy budget of urban landscapes. Meteorol. Atmos. Phys. 102, 187207.

Gebreslasie, M.T., Ahmed, F.B., Van Aardt, J.A.N., \& Blakeway, F. (2011). Individual tree detection based on variable and fixed window size local maxima filtering applied to IKONOS imagery for even-aged Eucalyptus plantation forests. International Journal of Remote Sensing, 32, 4141-4154.

Gonçalves, J.L.d.M., Stape, J.L., Laclau, J.-P., Smethurst, P., Gava, J.L., 2004. Silvicultural effects on the productivity and wood quality of eucalypt plantations. Forest Ecology and Management 193, 45-61.

Gougeon, F. A., 1995. A Crown-following approach to the automatic delineation of individual tree crowns in high spatial resolution aerial Images. Canadian Journal of Remote Sensing, 21, 274-284.

Hirschmugl, M., Ofner, M., Raggam, J., \& Schardt, M. (2007). Single tree detection in very high resolution remote sensing data. Remote Sensing of Environment, 110, 533-544.

Hummel, S., Hudak, A.T., Uebler, E.H., Falkowski, M.J., \& Megown, K.A. (2011). A comparison of accuracy and cost of LiDAR versus stand exam data for landscape management on the Malheur National Forest. Journal of forestry, 267-273.

Jacobsen, M., 2006. Point process theory and applications: marked point and piecewise deterministic processes. Springer Science \& Business, New York, USA.

Korpela, I. (2004). Individual tree measurements by means of digital aerial photogrammetry. Silva Fennica Monograph, 3, 93 pages. 
Laclau, J.-P., Ranger, J., Gonçalves, J.L.M., Maquère, V., Krusche, A.V., M'Bou, A.T., Nouvellon, Y., Saint-André, L., Bouillet, J.-P., de Cassia Piccolo, M., Deleporte, P., 2010. Biogeochemical cycles of nutrients in tropical Eucalyptus plantations: Main features shown by intensive monitoring in Congo and Brazil. Forest Ecology and Management 259, 1771-1785.

Larsen M., Rudemo, M., 1998. Optimizing templates for finding trees in aerial photographs. Pattern Recognition Letters, 19, 1153.1162.

Larsen, M., Eriksson, M., Descombes, X., Perrin, G., Brandtberg, T., Gougeon, F.A., 2011. Comparison of six individual tree crown detection algorithms evaluated under varying forest conditions. International Journal of Remote Sensing 32, 5827-5852.

le Maire, G., Marsden, C., Nouvellon, Y., Grinand, C., Hakamada, R., Stape, J.-L., Laclau, J.-P., 2011a. MODIS NDVI time-series allow the monitoring of Eucalyptus plantation biomass. Remote Sensing of Environment 115, 2613-2625.

le Maire, G., Marsden, C., Verhoef, W., Ponzoni, F.J., Lo Seen, D., Bégué, A., Stape, J.L., Nouvellon, Y., 2011b. Leaf area index estimation with MODIS reflectance time series and model inversion during full rotations of Eucalyptus plantations. Remote Sensing of Environment 115, 586-599.

le Maire, G., Nouvellon, Y., Christina, M., Ponzoni, F.J., Gonçalves, J.L.M., Bouillet, J.P., Laclau, J.P., 2012a. Tree and stand light use efficiencies over a full rotation of single- and mixed-species Eucalyptus grandis and Acacia mangium plantations. Forest Ecology and Management, http://dx.doi.org/10.1016/j.foreco.2012.03.005.

le Maire, G., Nouvellon, Y., Roupsard, O., Christina, M., Charbonnier, F., Zhou, J., Ponzoni, F., Stape, J.-L., Dauzat, J., Couteron, P., \& Proisy, C., 2012b. Very high resolution satellite images for parameterization of tree-scale forest process-based model. In: IGARSS 2012. Munich, Germany.

Marsden, C., le Maire, G., Stape, J.-L., Seen, D.L., Roupsard, O., Cabral, O., Epron, D., Lima, A.M.N., Nouvellon, Y., 2010. Relating MODIS vegetation index time-series with structure, light absorption and stem production of fast-growing Eucalyptus plantations. Forest Ecology and Management 259, 1741-1753.

Medlyn, B.E., 2004. A MAESTRO Retrospective. In: Mencuccini M., Moncrieff J., McNaughton K., J., G. (Eds.), Forests at the Land-Atmosphere Interface. CABI Publishing, Wallingford, UK, pp. 105-122.

Vauhkonen, J., Mehtätalo, L., \& Packalén, P. (2011). Combining tree height samples produced by airborne laser scanning and stand management records to estimate 
plot volume in Eucalyptus plantations. Canadian Journal of Forest Research, 41, 1649-1658.

Packalén, P., Mehtätalo, L., Maltamo, M., 2011. ALS-based estimation of plot volume and site index in a eucalyptus plantation with a nonlinear mixed-effect model that accounts for the clone effect. Annals of Forest Science 68, 1085-1092.

Pallett, R.N., Sale, G., 2004. The relative contributions of tree improvement and cultural practice toward productivity gains in Eucalyptus pulpwood stands. Forest Ecology and Management 193, 33-43.

Perrin, G., Descombes, X., Zerubia, J., Boureau, J.G., 2006. Forest resource assessment using stochastic geometry. In, International Precision Forestry Symposium, South Africa.

Pitkänen, J., 2001. Individual tree detection in digital aerial images by combining locally adaptive binarization and local maxima methods. Canadian Journal of Forest Research 31, 832-844.

Ploton, P., Pélissier, R., Proisy, C., Flavenot, T., Barbier, N., Rai, S.N., Couteron, P., 2012. Assessing aboveground tropical forest biomass using Google Earth canopy images. Ecological Applications 22, 993-1003.

Pouliot, D., King, D., Pitt, D., 2005. Development and evaluation of an automated tree detection-delineation algorithm for monitoring regenerating coniferous forests. Canadian Journal of Forest Research 35, 2332-2345.

Pouliot, D., King, D., 2005. Approaches for optimal automated individual tree crown detection in regenerating coniferous forests. Canadian Journal of Remote Sensing 31, 255-267.

Proisy, C., Couteron, P., Fromard, F., 2007. Predicting and mapping mangrove biomass from canopy grain analysis using Fourier-based textural ordination of IKONOS images. Remote Sensing of Environment 109, 379-392.

Proisy, C., Gratiot, N., Anthony, E.J., Gardel, A., Fromard, F., Heuret, P., 2009. Mud bank colonization by opportunistic mangroves: A case study from French Guiana using lidar data. Continental Shelf Research, 29, 632-641.

Richardson, J.J., \& Moskal, L.M. (2011). Strengths and limitations of assessing forest density and spatial configuration with aerial LiDAR. Remote Sensing of Environment, 115, 2640-2651.

Song, C., Dickinson, M.B., Su, L., Zhang, S., \& Yaussey, D. (2010). Estimating average tree crown size using spatial information from Ikonos and QuickBird images: Across- 
sensor and across-site comparisons. Remote Sensing of Environment, 114, 10991107.

Stape, J.L., Binkley, D., Ryan, M.G., Fonseca, S., Loos, R.A., Takahashi, E.N., Silva, C.R., Silva, S.R., Hakamada, R.E., Ferreira, J.M.d.A., Lima, A.M.N., Gava, J.L., Leite, F.P., Andrade, H.B., Alves, J.M., Silva, G.G.C., Azevedo, M.R., 2010. The Brazil Eucalyptus Potential Productivity Project: Influence of water, nutrients and stand uniformity on wood production. Forest Ecology and Management 259, 16841694.

Stephens, P.R., Kimberley, M.O., Beets, P.N., Paul, T.S.H., Searles, N., Bell, A., Brack, C., \& Broadley, J. (2012). Airborne scanning LiDAR in a double sampling forest carbon inventory. Remote Sensing of Environment, 117, 348-357.

Stoyan, D., Kendall, W.S., Mecke, J., Kendall, D.G., 1995. Stochastic Geometry and Its Applications. John Wiley \& Sons, Chichester.

Tesfamichael, S.G., Ahmed, F., van Aardt, J.A.N., \& Blakeway, F. (2009). A semivariogram approach for estimating stems per hectare in Eucalyptus grandis plantations using discrete-return lidar height data. Forest Ecology and Management, 258, 1188-1199.

Vanclay, J.K. 1994. Modelling Forest Growth and Yield: Applications to Mixed Tropical Forests. CABI, Wallingford, UK. 312 p.

van Lieshout, M.N.M., 2000. Markov point processes and their applications. Imperial College Press, London.

Vauhkonen, J., Ene, L., Gupta, S., Heinzel, J., Holmgren, J., Pitkänen, J., Solberg, S., Wang, Y., Weinacker, H., Hauglin, K.M., Lien, V., Packalén, P., Gobakken, T., Koch, B., Næsset, E., Tokola, T., \& Maltamo, M. (2012). Comparative testing of single-tree detection algorithms under different types of forest. Forestry, 85, 27-40.

Walters, G.A. (1980). Saligna eucalyptus growth in a 15 -year-old spacing study in Hawaii. Pacific Southwest Forest and Range Experiment Station, 151, 1-6.

Wulder, M.A., White, J.C., Niemann, K.O., Nelson, T., 2004. Comparison of airborne and satellite high spatial resolution data for the identification of individual trees with local maxima filtering. International Journal of Remote Sensing 25, 2225-2232. 


\section{Table 1}

Main acquisition parameters for Worldview images.

\begin{tabular}{lccccccc}
\hline Satellite & $\begin{array}{c}\text { Date of } \\
\text { acquisition }\end{array}$ & $\begin{array}{c}\text { Acquisition } \\
\text { time (GMT) }\end{array}$ & $\begin{array}{c}\text { Spatial } \\
\text { resolution } \\
(\mathrm{m})\end{array}$ & $\begin{array}{c}\text { Sensor } \\
\text { azimuth } \\
\text { angle }\left({ }^{\circ}\right)\end{array}$ & $\begin{array}{c}\text { Sensor } \\
\text { elevation } \\
\text { angle }\left({ }^{\circ}\right)\end{array}$ & $\begin{array}{c}\text { Sun } \\
\text { Azimuth } \\
\text { angle }\left({ }^{\circ}\right)\end{array}$ & $\begin{array}{c}\text { Sun } \\
\text { Elevation } \\
\text { angle }\left({ }^{\circ}\right)\end{array}$ \\
\hline Worldview2 & 11-May-10 & $13: 29$ & 0,5 & 53,5 & 70,7 & 33,5 & 68,1 \\
\hline Worldview2 & 01-Aug-10 & $13: 43$ & 0,5 & 297,7 & 83,2 & 32,5 & 42,7 \\
\hline Worldview1 & 29-Jan-11 & $13: 50$ & 0,5 & 337,6 & 81,6 & 82,3 & 66,7 \\
\hline
\end{tabular}

\section{Table 2}

Median scores obtained using various $\left[r_{\min }, r_{\max }\right]$ pairs and in comparison with the two visual expert appraisals. Minimum and maximum scores are given in brackets.

\begin{tabular}{|c|c|c|c|c|c|c|c|c|c|c|}
\hline \multirow{2}{*}{$r_{\min }$} & \multirow{2}{*}{$r_{\max }$} & \multirow{2}{*}{$\begin{array}{c}\text { Number } \\
\text { of } \\
\text { couples }\end{array}$} & \multicolumn{2}{|c|}{$\mathrm{Al}(\%)$} & \multicolumn{2}{|c|}{ Omitted detections } & \multicolumn{2}{|c|}{ Single detections } & \multicolumn{2}{|c|}{ Multiple detections } \\
\hline & & & Expert \#1 & Expert \#2 & Expert \#1 & Expert \#2 & Expert \#1 & Expert \#2 & Expert \#1 & Expert \#2 \\
\hline \multirow[b]{2}{*}{7} & \multirow[b]{2}{*}{$8-12$} & \multirow[b]{2}{*}{5} & 82.8 & 84.9 & 1.6 & 2.2 & 90.6 & 91.9 & 5.4 & 3.7 \\
\hline & & & $\begin{array}{l}(68.4- \\
95.2)\end{array}$ & $\begin{array}{l}(69.1- \\
94.8)\end{array}$ & $\begin{array}{l}(0.0- \\
10.7)\end{array}$ & $\begin{array}{l}(0.0- \\
12.4)\end{array}$ & $\begin{array}{l}(81.2- \\
97.5)\end{array}$ & $\begin{array}{l}(81.7- \\
97.3)\end{array}$ & $\begin{array}{l}(0.7- \\
15.2)\end{array}$ & $\begin{array}{l}\text { (0.9- } \\
13.3)\end{array}$ \\
\hline \multirow[b]{2}{*}{8} & \multirow[b]{2}{*}{$9-12$} & \multirow[b]{2}{*}{4} & 83.2 & 86.4 & 3.9 & 3.8 & 90.8 & 92.7 & 3.3 & 2.6 \\
\hline & & & $\begin{array}{c}(70.1- \\
93.3)\end{array}$ & $\begin{array}{c}(72.1- \\
94.8)\end{array}$ & $\begin{array}{l}(0.7- \\
10.7)\end{array}$ & $\begin{array}{l}(0.2- \\
13.1)\end{array}$ & $\begin{array}{c}(82.4- \\
96.5)\end{array}$ & $\begin{array}{c}(83.8- \\
97.3)\end{array}$ & $\begin{array}{l}(0.7- \\
11.6)\end{array}$ & $(0.7-7.9)$ \\
\hline \multirow[b]{2}{*}{9} & \multirow[b]{2}{*}{$10-12$} & \multirow[b]{2}{*}{3} & 81.2 & 84.8 & 5.7 & 4.4 & 89.6 & 91.4 & 2.9 & 2.3 \\
\hline & & & $\begin{array}{l}(70.6- \\
95.7)\end{array}$ & $\begin{array}{l}(70.9- \\
94.7)\end{array}$ & $\begin{array}{l}(1.6- \\
13.5)\end{array}$ & $\begin{array}{l}(0.8- \\
14.2)\end{array}$ & $\begin{array}{c}(82.7- \\
97.8)\end{array}$ & $\begin{array}{c}(83.0- \\
97.1)\end{array}$ & $(0.5-9.3)$ & \\
\hline \multirow[b]{2}{*}{10} & \multirow[b]{2}{*}{$11-12$} & \multirow[b]{2}{*}{2} & 75.9 & 76.4 & 11.4 & 11.3 & 86.3 & 86.6 & 1.9 & 0.8 \\
\hline & & & $\begin{array}{c}(65.2- \\
91.1)\end{array}$ & $\begin{array}{c}(66.2- \\
92.7)\end{array}$ & $\begin{array}{l}(3.8- \\
19.0)\end{array}$ & $\begin{array}{l}\text { (3.5- } \\
19.1)\end{array}$ & $\begin{array}{c}(78.9- \\
95.4)\end{array}$ & $\begin{array}{c}(79.6- \\
96.2)\end{array}$ & $(0.5-5.4)$ & \\
\hline
\end{tabular}




\section{FIGURE CAPTIONS}

Figure 1. Extract from the Worldview image acquired in August 2010 of the Eucalyptus plantation area and location of the study site near São Paulo, Brazil (box map). The four zones of different plantation row azimuths are noted $A$ to $D$. The four filled frames inside zones $C$ and $D$ indicate the areas where extensions of tree crowns were recorded on a total of $4 \times 83$ trees. The empty square frames symbolize the 18 training plots (each of $50 \times 50 \mathrm{~m}$ ) from which the visual analysis was completed. The filled white square frames represent the 112 ground truth plots where tree counting was obtained from a field inventory undertaken in May 2010.

Figure 2. Appearance of the four plantation row orientations (from left to right) from selected 50x50m Worldview images in May, August and January (from top to bottom). Crown size variability and variation of local tree density of trees are also apparent.

Figure 3. Flowchart of processing steps.

Figure 4. Illustration based on a particular configuration of three disc-objects of the main aspects of marked point process fitting. Left: Illustration of overlapping area $A$ between two disc-objects and principles defining the prior energy term in relation to the overlapping threshold $\theta$. Right: Example of circular disc-objects as positioned on a $10 \mathrm{~cm}$ pixels image to maximize reflectance contrasts between discs and surrounding rings. The inset shows the position of the illustration within the embedding system of rows.

Figure 5. Effect of overlapping threshold $\theta$ on detection quality for May (6 months after planting, top), August ( 9 months, middle) and January (13 months, bottom) images. Circular dots indicate accuracy index $A l$ (see text). Square, star and triangle markers correspond to rates of validated, multiple and omitted detections, respectively. All values are averaged over three plots from those inside zones $A, C$ or D (one per zone) using three values of data energy threshold $T$ values of $0.05,0.1$ and 0.2 . The standard error in overall accuracy index is represented by dashed lines.

Figure 6. Results from the MPP-based modeling of the image acquired in August with $\gamma=2, T=0.2$ and $\theta=0.2$ (see text). Detection rates and accuracy index are computed for the four zones of the plantation and for each expert visual interpretation as median values over the $\left[r_{\min }, r_{\max }\right]$ intervals listed in table 3 . Circular dots indicate the accuracy index AI. Square, star and triangle markers correspond to rates of validated, multiple and omitted detections, respectively.

Figure 7. Example of MPP detection results obtained over the 4 plots presented in figure 2 using the best parameters combination established for the August image analysis i.e. $\gamma=2, T=0.2$ and $\theta=0.2$ and $\left[r_{\min }, r_{\max }\right]=[8,11]$. Yellow discs with ' + ' indicate single detections. Blue square dots and green triangles with ' $x$ ' indicate multiple detection and no detections, respectively.

Figure 8. Comparison between local density values obtained from a field survey and from MPP analysis. Two plots of strongly contrasting tree density are shown. The solid black line gives the regression line of the form $Y=a \times X$ (intercept coerced to zero). 
50 Figure 9. Example of a local tree density map computed over the entire plantation at $5150 \times 50 \mathrm{~m}$ resolution of the marked point process modelling. Masked areas are centered 52 along the road network. 
Figure 1

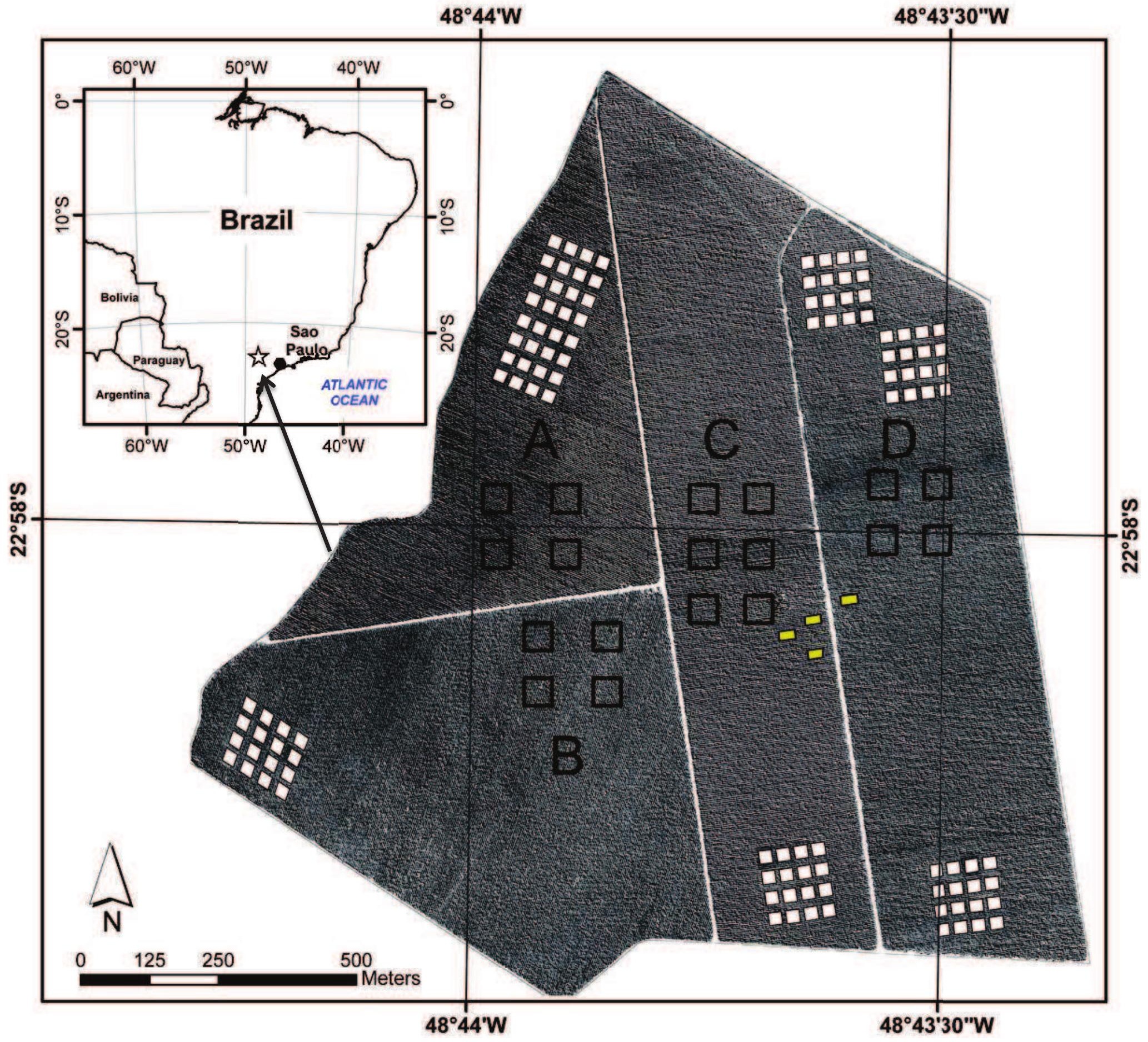


Figure 2

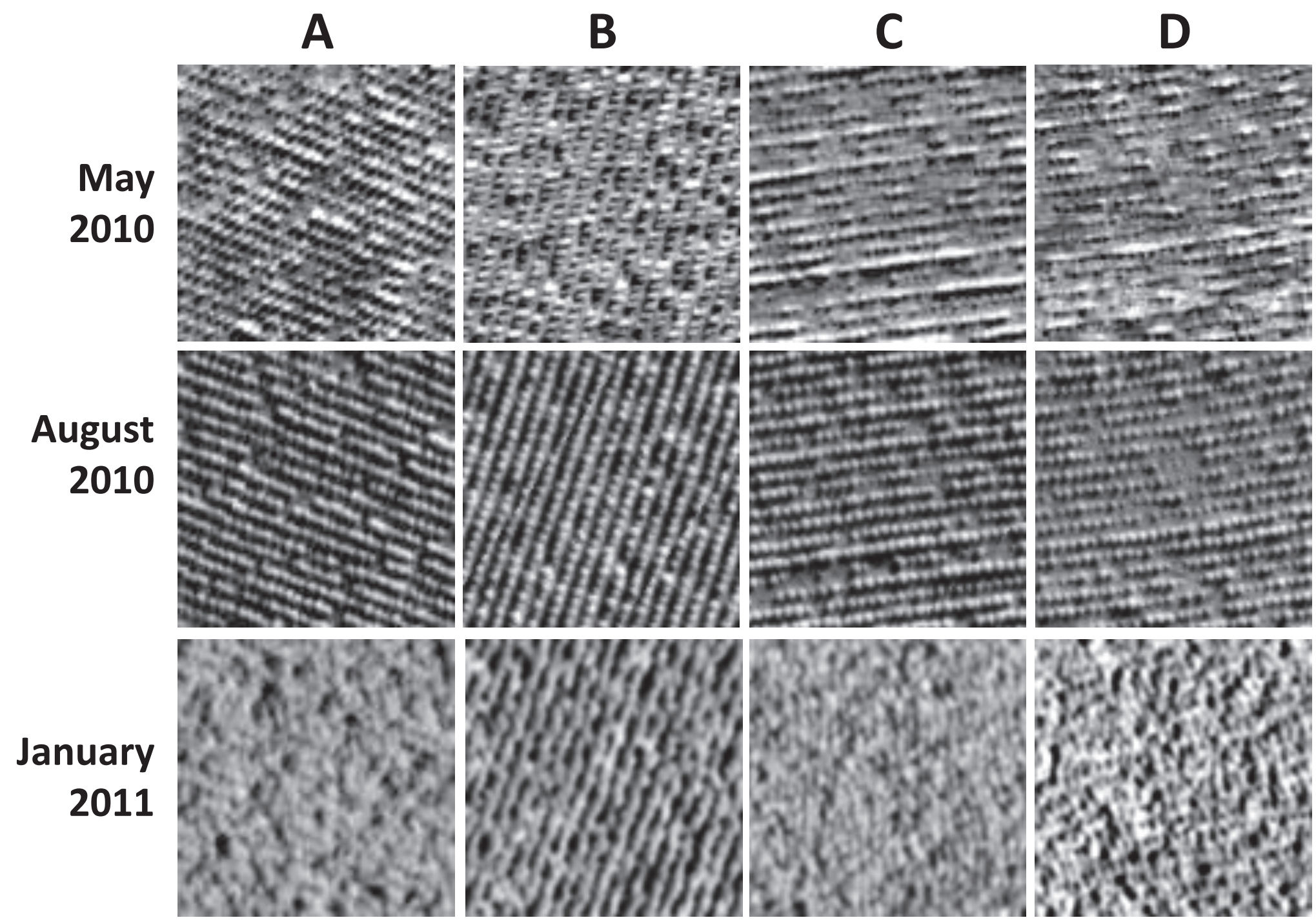


$10 \mathrm{~cm}$ oversampled optical images

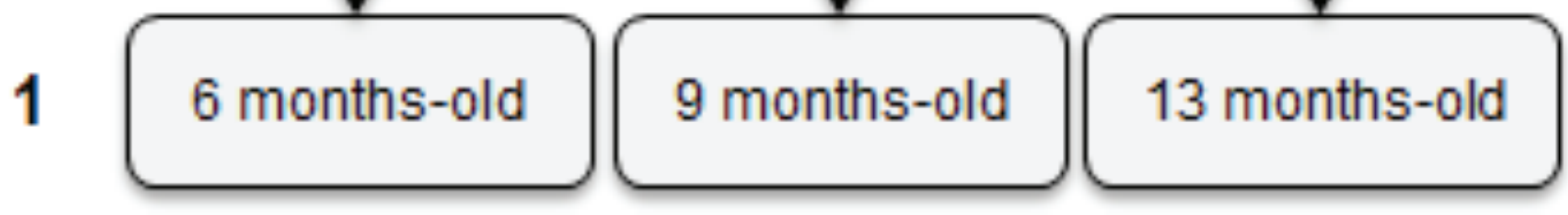

Visual tree positions

$\sim 2 \times 7000$ trees

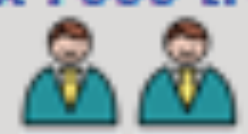

L
MPP-derived tree positions

3 acquisitiondates and different $\gamma, T, \Theta$

3

Best parameters combinations for MPP-based tree detections

\section{Ground truth validation of MPP-derived local density 112 plots of $\sim 96$ trees}




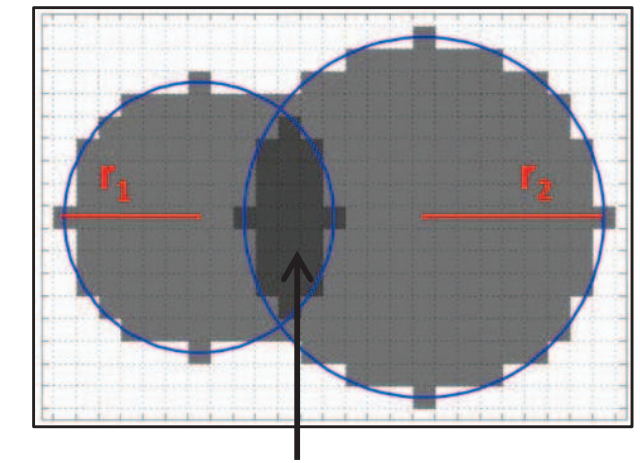

Overlapping area $A$

Prior energy adjustment:

$A=0$ no overlap, no penalization $A<\theta$ acceptable but penalized $A \geq \theta$ forbidden

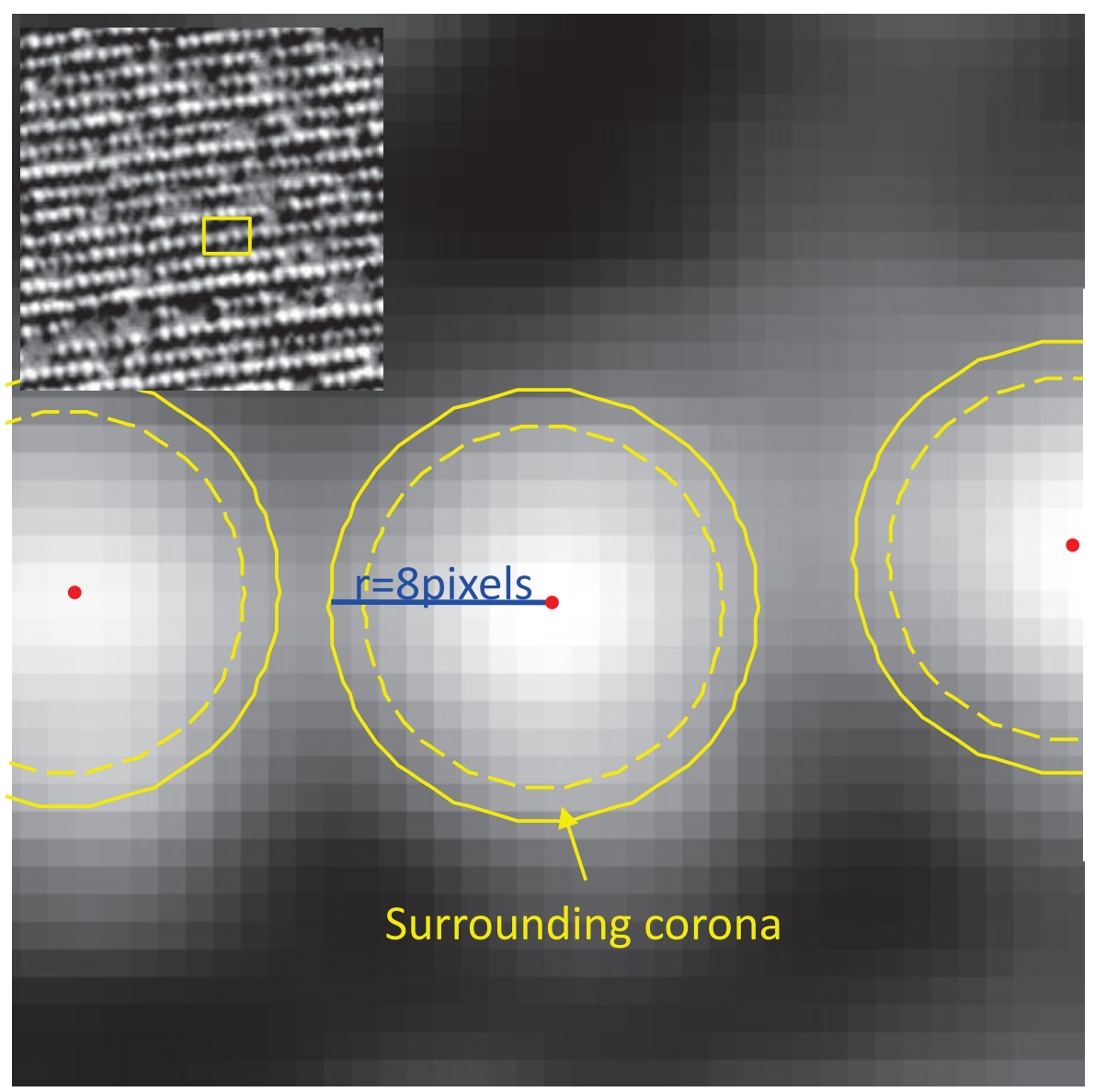


Figure 5
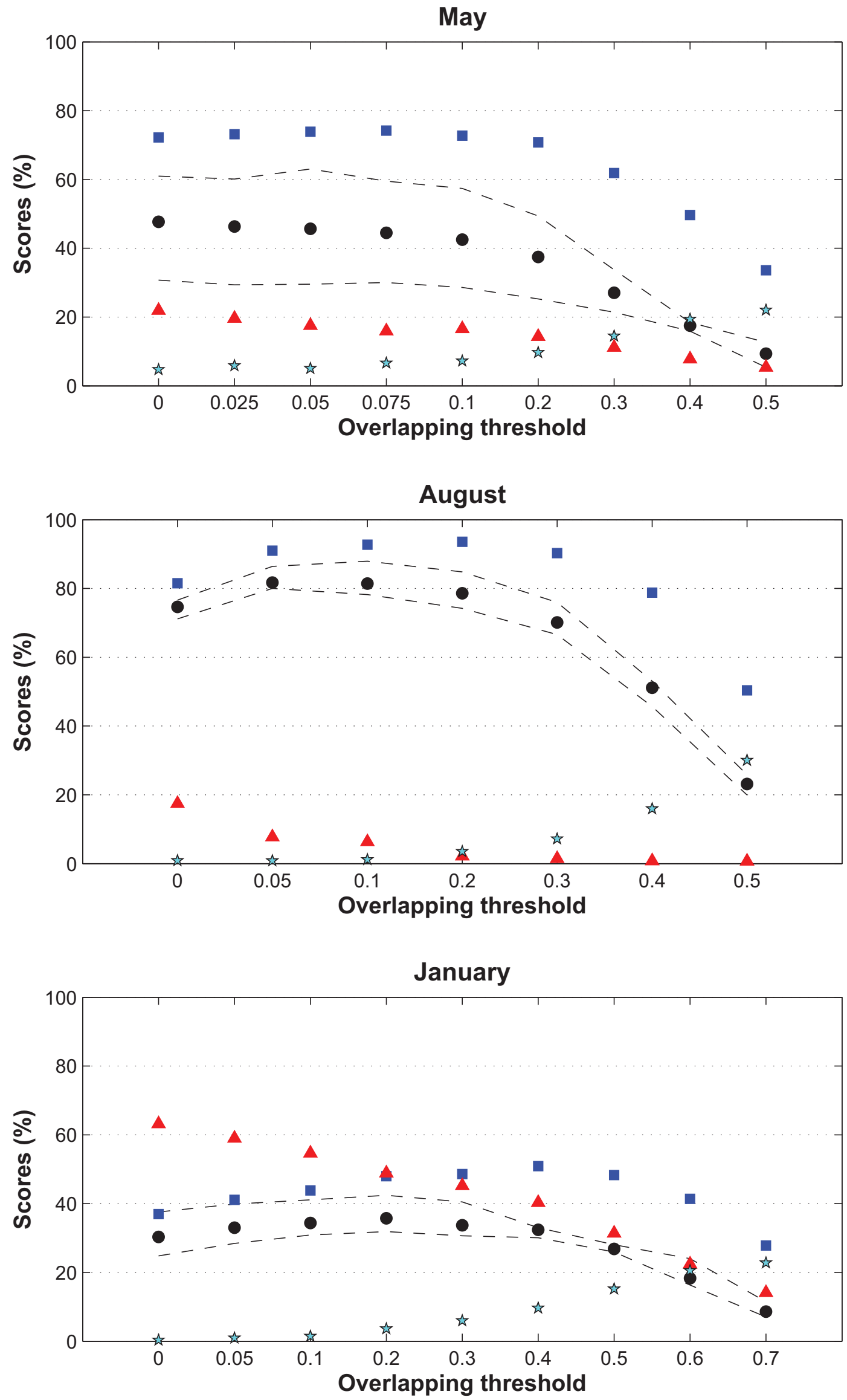
Figure 6

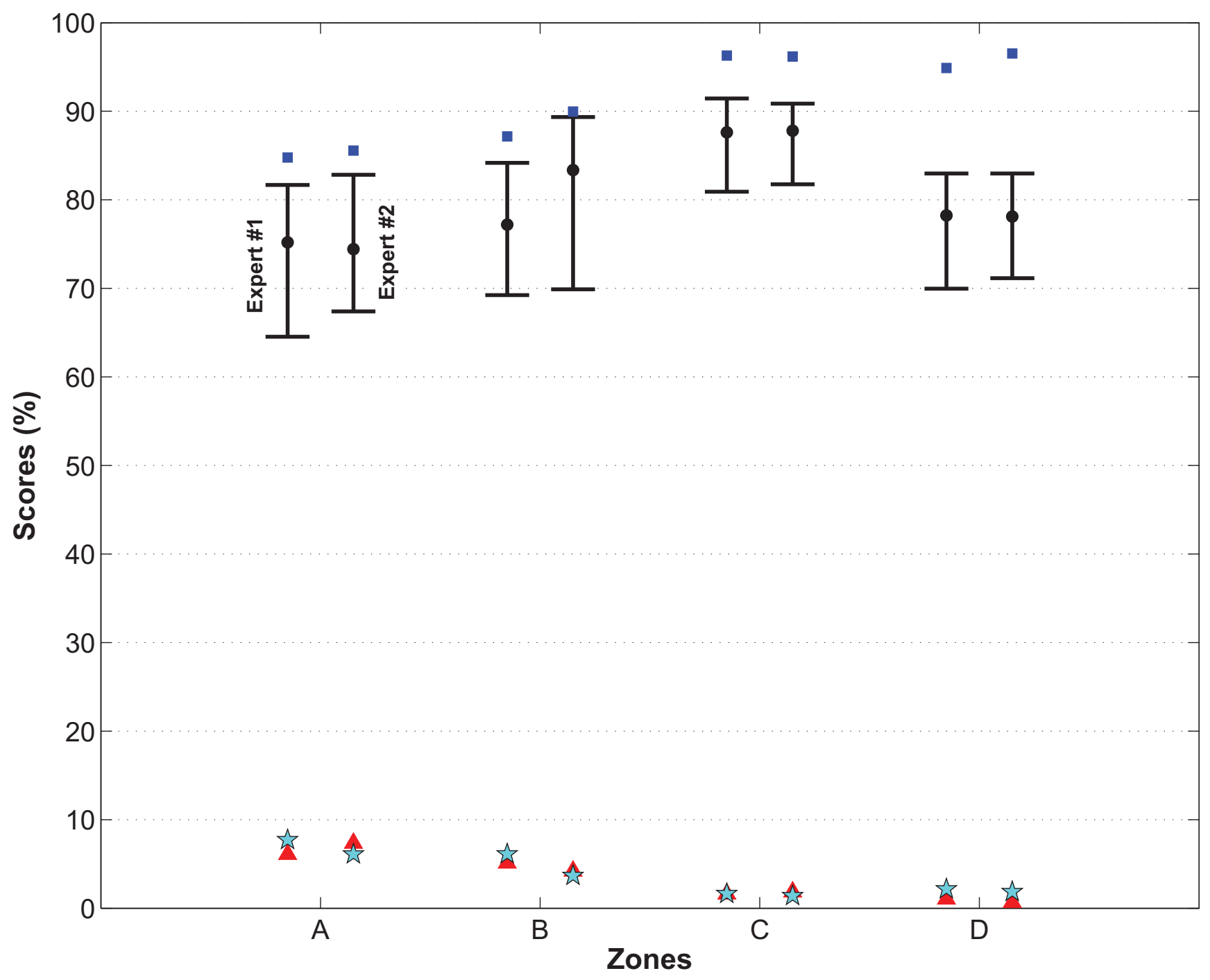



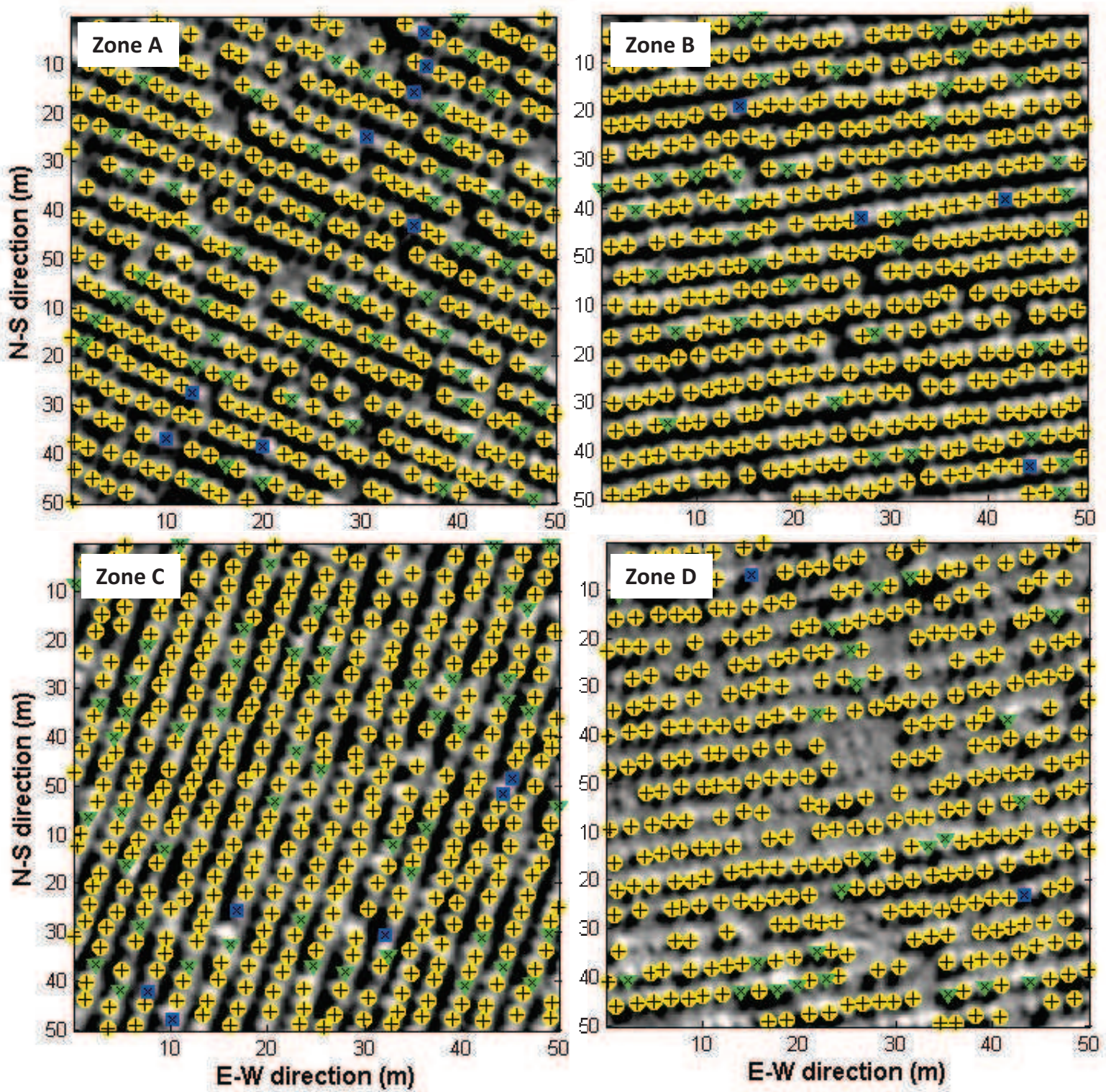


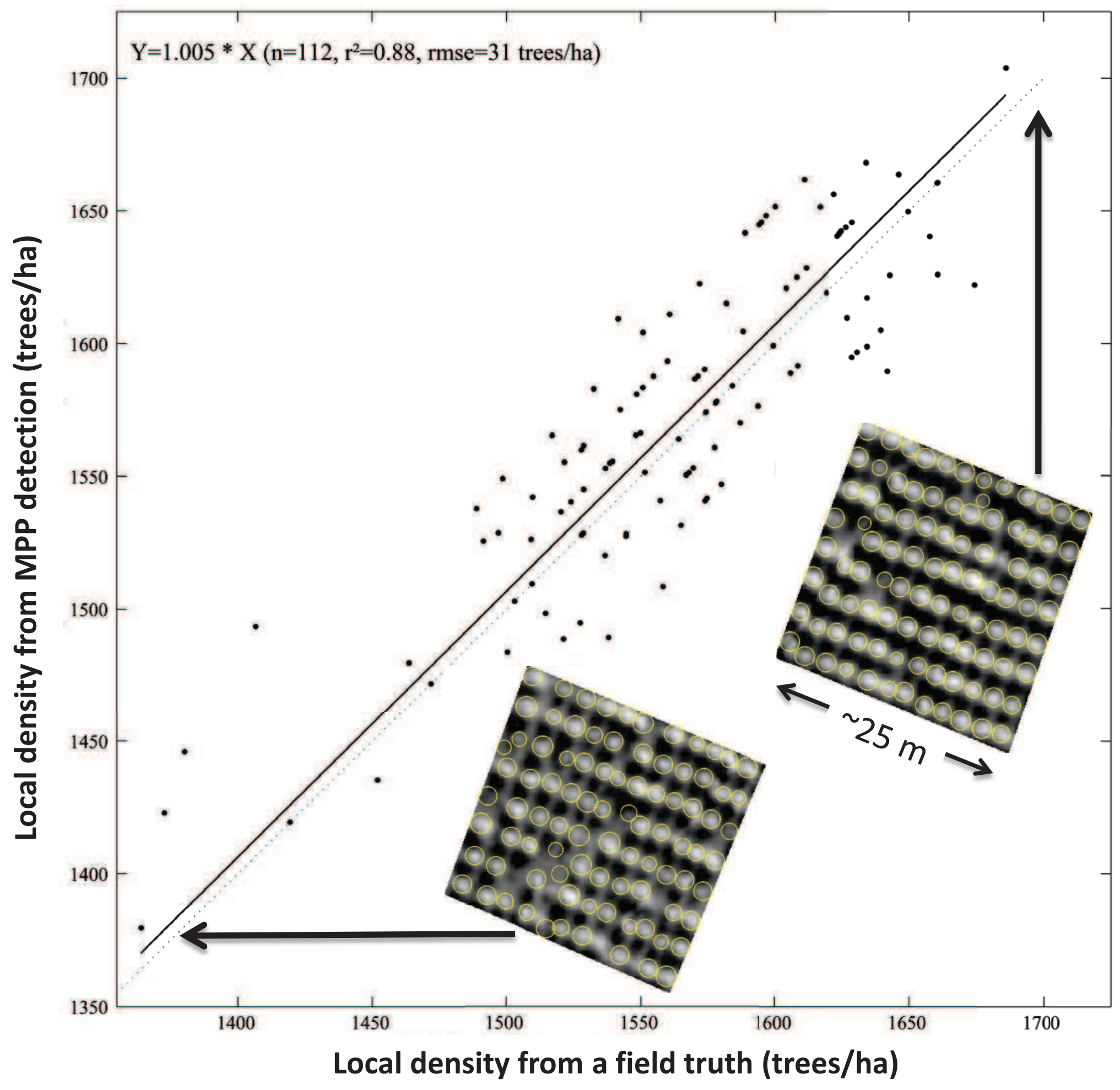




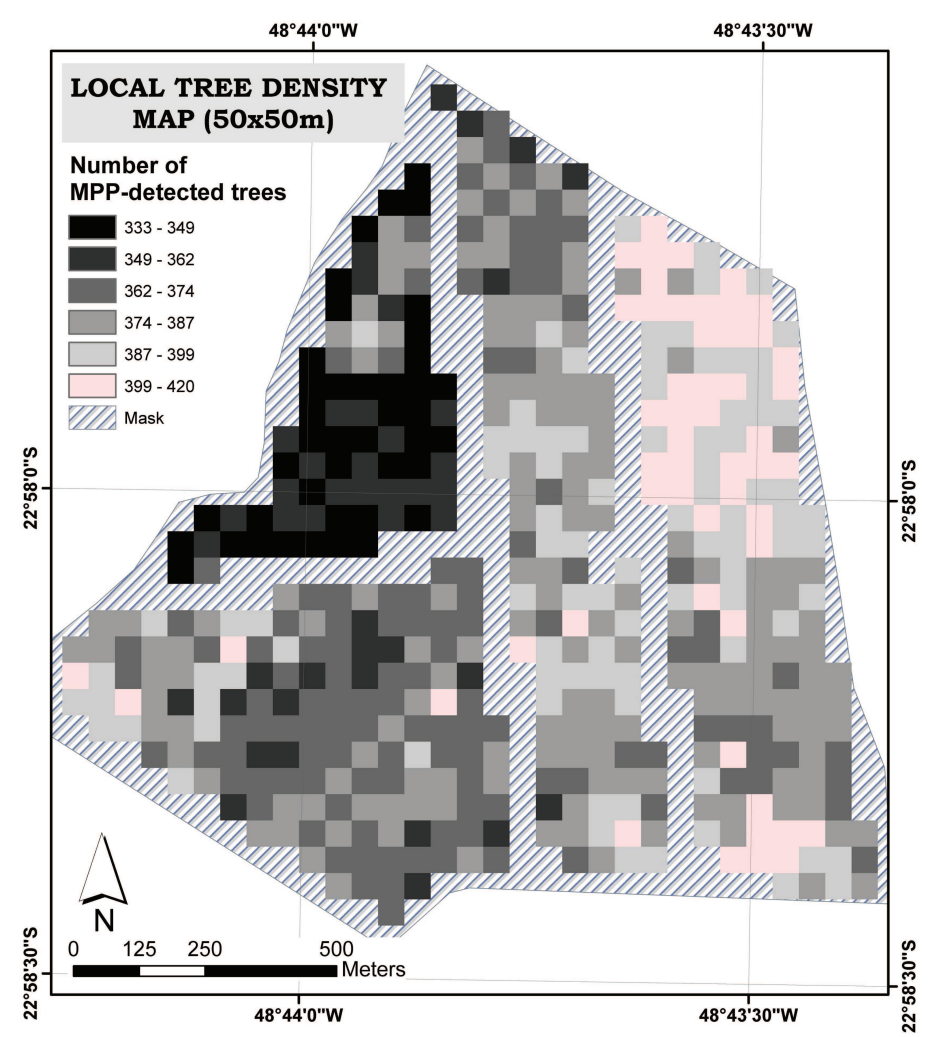

